\title{
Control of nanoparticle size, reactivity and magnetic properties during the bioproduction of magnetite by Geobacter sulfurreducens
}

J. M. Byrne ${ }^{1 *}$, N. D. Telling ${ }^{2}$, V. S. Coker ${ }^{1}$, R. A. D. Pattrick ${ }^{1}$, G. van der Laan ${ }^{1,3}$, E. Arenholz $^{4}$, F. Tuna ${ }^{5}$ and J. R. Lloyd ${ }^{1}$

${ }^{1}$ School of Earth, Atmospheric and Environmental Sciences and Williamson Research Centre for Molecular Environmental Science, University of Manchester, Manchester M13 9PL, UK

${ }^{2}$ Institute for Science \& Technology in Medicine, Keele University, Stoke-on-Trent ST4 $7 Q B, U K$

${ }^{3}$ Diamond Light Source, Didcot, Oxfordshire OX11 ODE, UK

${ }^{4}$ Advanced Light Source, Lawrence Berkeley National Laboratory, Berkeley, California 94720, USA

${ }^{5}$ School of Chemistry, University of Manchester M13 9PL, UK

*corresponding author: James.Byrne@postgrad.manchester.ac.uk

\begin{abstract}
The bioproduction of nano-scale magnetite by Fe(III)-reducing bacteria offers a potentially tunable, environmentally benign route to magnetic nanoparticle synthesis. Here, we demonstrate that it is possible to control the size of magnetite nanoparticles produced by Geobacter sulfurreducens, by adjusting the total biomass introduced at the start of the process. The particles have a narrow size distribution and can be controlled within the range of 10-50 nm. X-ray diffraction analysis indicates that controlled production of a number of different
\end{abstract}


biominerals is possible via this method including goethite, magnetite and siderite, but their formation is strongly dependent upon the rate of $\mathrm{Fe}(\mathrm{III})$ reduction and total concentration and rate of $\mathrm{Fe}$ (II) produced by the bacteria during the reduction process.

Relative cation distributions within the structure of the nanoparticles has been investigated by X-ray magnetic circular dichroism and indicates the presence of a highly reduced surface layer which is not observed when magnetite is produced through abiotic methods. The enhanced Fe(II)-rich surface, combined with small particle size, has important environmental applications such as in the reductive bioremediation of organics, radionuclides and metals. In the case of $\mathrm{Cr}(\mathrm{VI})$, as a model high-valence toxic metal, optimised biogenic magnetite is able to reduce and sequester the toxic hexavalent chromium very efficiently in the less harmful trivalent form.

Keywords: Magnetite, Fe(III)-reduction, XMCD, Geobacter, control, diameter, chromium

\section{Introduction}

Nanometre sized particles have unique applications in areas ranging from computer technology, waste water cleanup, catalysis and medical treatments such as cancer therapy and drug delivery [1-6]. Magnetic nanoparticles (MNPs), in particular magnetite $\left(\mathrm{Fe}_{3} \mathrm{O}_{4}\right)$, offer some of the most promising alternatives to conventional therapeutic agents due to their small size and intrinsic magnetic properties. The ability to control and manipulate these properties would allow for the tailoring of the particles to specific applications. For example in biomedicine, superparamagnetic iron oxide nanoparticles (SPIONs) with diameters below $\sim 20$ $\mathrm{nm}$ are best suited to applications such as cancer therapies and magnetic resonance imaging (MRI).

Many synthetic approaches to magnetite formation require high temperatures and toxic reagents, which are both expensive and environmentally undesirable. The control of particle size using some of these techniques often requires convoluted processes and the use of organic reagents such as solvents [7] which renders them unsuitable for insertion into the human body. This paper presents an alternative approach to the production and precise control of the particle size of magnetic nanoparticles using the subsurface Fe(III)-reducing bacterium Geobacter sulfurreducens, which is able to generate large amounts of extracellular magnetite at ambient temperatures.

Metal-reducing bacteria conserve energy for growth in anoxic environments through the oxidation of an electron donor (such as organic matter) coupled with the reduction of oxidised metal cations, for example $\mathrm{Fe}^{3+}$ in compounds including $\mathrm{Fe}(\mathrm{III})$-oxyhydroxides. The reduction of solid-phase $\mathrm{Fe}(\mathrm{III})$ leads to the release of soluble $\mathrm{Fe}^{2+}$ which recrystallises into new 
mineral phases ranging from goethite, magnetite, siderite to vivianite depending on the conditions of formation such as buffer, $\mathrm{pH}$ and temperature $[8,9]$.

Magnetite has an inverse spinel structure, with chemical formula $\left(\mathrm{Fe}^{3+}\right)^{\mathrm{Td}}\left(\mathrm{Fe}^{2+} \mathrm{Fe}^{3+}\right)^{\mathrm{Oh}} \mathrm{O}_{4}{ }^{2-}$ which consists of tetrahedral $\left(\mathrm{T}_{\mathrm{d}}\right)$ and octahedral $\left(\mathrm{O}_{\mathrm{h}}\right)$ sites. In stoichiometric form, $\mathrm{Fe}^{3+}$ occupies both sites equally while $\mathrm{Fe}^{2+}$ is only situated in the octahedral sites, resulting in a distribution of $1: 1: 1$ at the $\mathrm{Fe}^{2+} \mathrm{O}_{\mathrm{h}}: \mathrm{Fe}^{3+} \mathrm{T}_{\mathrm{d}}: \mathrm{Fe}^{3+} \mathrm{O}_{\mathrm{h}}$ sites. Antiparallel magnetic moments of the $\mathrm{Fe}^{3+}$ cations on the $\mathrm{T}_{\mathrm{d}}$ and $\mathrm{O}_{\mathrm{h}}$ sites cancel out, resulting in zero net magnetization, whereas the $\mathrm{Fe}^{2+}$ moments at the $\mathrm{O}_{\mathrm{h}}$ sites have no magnetic opponents, resulting in the ferrimagnetism exhibited by magnetite at room temperature.

In addition to the magnetic properties, $\mathrm{Fe}_{3} \mathrm{O}_{4}$ MNPs also have important uses due to external reactivity created by a large surface/volume ratio. In this study the variation in the reactivity of the nanoparticles was investigated through reaction with potassium chromate $\left(\mathrm{K}_{2} \mathrm{CrO}_{4}\right)$. The reduction and immobilisation of highly soluble, potentially carcinogenic $\mathrm{Cr}(\mathrm{VI})$ to less harmful $\mathrm{Cr}$ (III) has many important environmental consequences, particularly in ground waters that contain high concentrations of $\mathrm{Cr}(\mathrm{VI})$ due to industrial or mining processes. $\mathrm{Fe}(\mathrm{II})$ bearing minerals, such as magnetite, have been shown to offer a potential route for chromium remediation [10] through the reduction of $\mathrm{Cr}(\mathrm{VI})$ and incorporation of the $\mathrm{Cr}(\mathrm{III})$ cations into octahedral sites of the magnetite spinel structure [11].

This study demonstrates the manipulation of the size of biogenic magnetite particles through the careful control of biomass levels during the conversion of $\mathrm{Fe}$ (III)-oxyhydroxides to magnetite by whole cells of Geobacter sulfurreducens [12]. Crystallographic properties such as lattice structure and site occupancies of the iron within the biogenic magnetite have been probed using a variety of techniques such as powder X-ray diffraction (PXRD), transmission electron microscopy (TEM), X-ray absorption spectroscopy (XAS) and X-ray magnetic circular dichroism (XMCD). The bulk magnetic signatures of the samples were investigated using superconducting quantum interference device (SQUID) magnetometry. The potential for contaminant reduction was also measured using a $\mathrm{Cr}(\mathrm{VI})$ assay supported by ICP-AES analysis. 


\section{Results and discussion}

Powder X-ray diffraction (PXRD) was used to determine the changes in particle size and iron mineral phases that were produced through the reduction of $\mathrm{Fe}$ (III)-oxyhydroxide inoculated with biomass between $\mathrm{OD}_{600}$ values of 0.015 and 4, corresponding to 0.005 and 1.5 $\mathrm{mg} / \mathrm{ml}$ cellular protein, respectively. $\mathrm{OD}_{600}$ corresponds to the optical density of the culture in growth medium as measured by the absorption of light by a cell suspension at a wavelength of $600 \mathrm{~nm}$. The conversion of $\mathrm{OD}_{600}$ values to protein content $(\mathrm{mg} / \mathrm{ml})$ is detailed in the methods section of this paper. These experiments were conducted in the presence of the electron shuttling compound and humic analogue anthraquinone-2,6-disulfonate (AQDS) (figure 1a). Goethite $(\alpha-\mathrm{FeOOH})$ was the predominant end product at low concentrations of biomass, with magnetite formed at intermediate concentrations, and evidence of siderite $\left(\mathrm{FeCO}_{3}\right)$ formation at the highest biomass concentrations. The sample with $\mathrm{OD}_{600}=0.2(0.06 \mathrm{mg} / \mathrm{ml}$ protein $)$ displays peaks corresponding to both magnetite and goethite. Magnetite is the only crystalline material observed within the range $0.4 \leq \mathrm{OD}_{600} \leq 1.0$, with a reflection at $2 \theta \approx 32^{\circ}$ representing siderite formation at the highest optical densities $\left(\mathrm{OD}_{600}=2\right.$ and 4$)$. It should be noted that in an analogous experiment, run simultaneously without AQDS, magnetite did not form until higher optical density values $\left(\mathrm{OD}_{600}=0.4\right)$ and there was no evidence of siderite formation at $\mathrm{OD}_{600}=$ 4. These results lend support to the suggestion that the mechanism underpinning iron biomineral formation is strongly dependent upon the rate of Fe(III)-reduction as AQDS greatly increases reduction rates [13], as do increased biomass (i.e. biocatalyst) levels. This may also have a bearing on the production of additional mineral phases such as goethite and siderite which are have been shown to be produced in $\mathrm{Fe}^{2+}$ poor, and $\mathrm{Fe}^{2+}$ rich environments respectively by several previous studies $[8,9,12,14]$. 

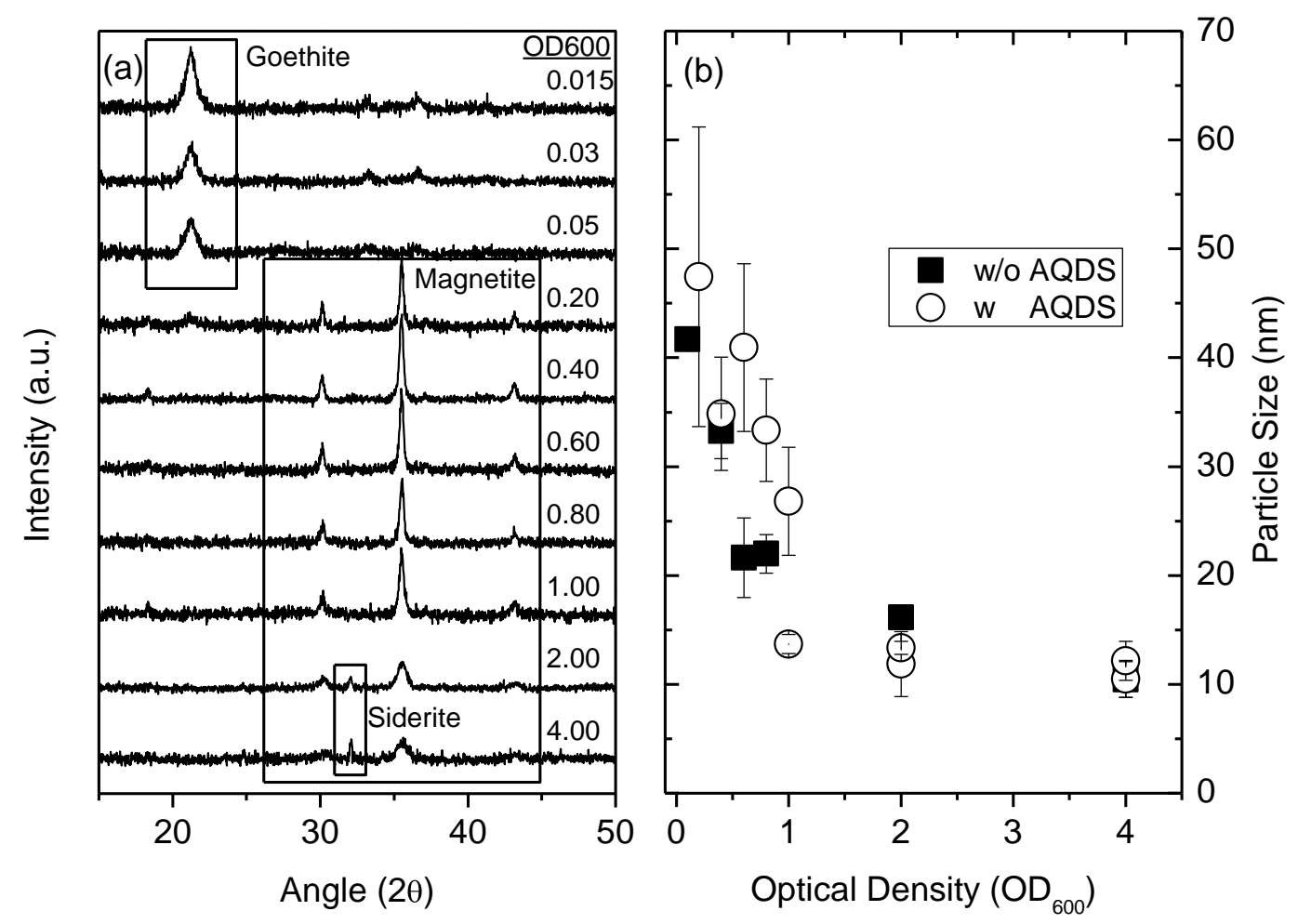

Figure 1. a) X-ray diffraction patterns observed for samples prepared with AQDS for several different optical densities $\left(\mathrm{OD}_{600}\right)$ of initial bacterial biomass. Different mineral phases formed depending on the $\mathrm{OD}_{600}$, including goethite, magnetite and siderite. b) Mean crystallite size for samples produced with and without the mediator AQDS, determined from the (llll $\left.\begin{array}{lll}3 & 1\end{array}\right),\left(\begin{array}{lll}2 & 2 & 0\end{array}\right)$ and (4 4 0) reflections of magnetite (error bars were determined from the standard deviation obtained by fitting the three peaks).

PXRD results reveal that the goethite and magnetite peaks became progressively broader and shorter as the biomass density used to catalyse Fe(III) reduction increased, concomitant with a decrease in the size of the crystallite obtained as an end product. The results of the size analysis using the magnetite ( $\left.\begin{array}{lll}3 & 1 & 1\end{array}\right),\left(\begin{array}{lll}2 & 2 & 0\end{array}\right)$ and (4 400$)$ reflections with and without the addition of AQDS in the starting culture are shown in figure $1 \mathrm{~b}$. The crystallite size decreased as the $\mathrm{OD}_{600}$ increased both with and without the electron shuttle. For the samples including the electron shuttle AQDS, the change of particle size with respect to optical density appears to be rapid before reaching a minimum size limit of $\sim 10 \mathrm{~nm}$ at $\mathrm{OD}_{600}=2$. In the samples without AQDS, a limit was not reached although the rate of decrease in crystallite size was decreasing with increasing $\mathrm{OD}_{600}$ and extrapolation would suggest a similar lower size limit.

Images produced using TEM for biomass levels corresponding to $\mathrm{OD}_{600}=0.4,1,2$ and 4 are presented in figure $2 a, b, c$ and $d$, respectively. These images confirm that the magnetite particles produced by $\mathrm{OD}_{600}=0.4$ are much larger and show more polydispersion of size than 
the other samples, with a mixture of particle shapes including spherical and square. Samples with higher biomass produced progressively smaller particles which were predominantly spherical and had a narrow size distribution. Goethite was not visible in any of the samples, either by examination of the images or through selective area electron diffraction (SAED), in keeping with the PXRD data. There was also no visible evidence of any siderite in samples $\mathrm{OD}_{600}=2$ and 4 , which was visible in the PXRD analysis, suggesting that it is a minor phase.

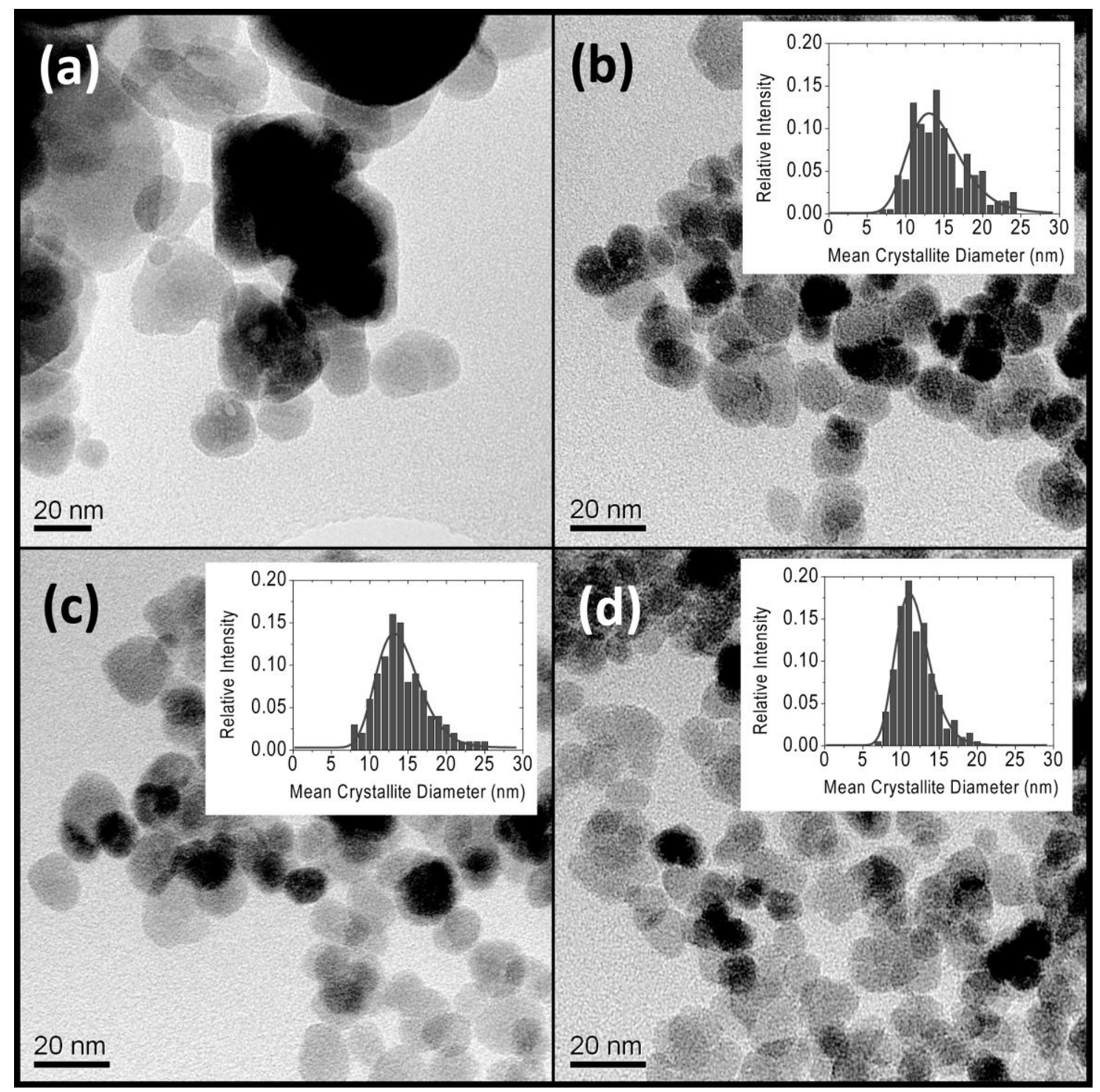

Figure 2. Transmission electron microscopy images of magnetite nanoparticles produced by Geobacter sulfurreducens with electron shuttle $\mathrm{AQDS}$. a) $\mathrm{OD}_{600}=0.4$, b) $\mathrm{OD}_{600}=1$, c) $\mathrm{OD}_{600}=2$ and d) $\mathrm{OD}_{600}=4$. Inset graphs indicate the differences in particle size distributions.

Size distributions were determined for the $\mathrm{OD}_{600}=1,2$ and 4 cultures, with 200 measurements applied for each (insets figures $2 \mathrm{~b}-\mathrm{d}$ ). The resulting distributions closely followed a log-normal function, for which a fit was applied to determine mean particle size and most probable particle size. The distributions observed are very narrow, an important property 
for technological applications, and the range reduces as the mean particle diameter decreases, as indicated by the dispersion index $\sigma_{\mathrm{d}}$ (table 1). The mean diameters, as determined by fitting of the log-normal distribution, closely match the values for crystallite size determined by PXRD (compared against samples that were produced with addition of AQDS).

Table 1. Structural and magnetic properties of biogenic magnetite produced at different biomass concentrations $\left(\mathrm{OD}_{600}\right)$. Results from TEM obtained using sample size $\mathrm{n}=200$ (n=number of particles).

$$
\begin{array}{cccc}
\mathrm{OD}_{600}=0.4 & \mathrm{OD}_{600}=1 & \mathrm{OD}_{600}=2 & \mathrm{OD}_{600}=4 \\
(0.14 \mathrm{mg} / \mathrm{ml}) & (0.38 \mathrm{mg} / \mathrm{ml}) & (0.76 \mathrm{mg} / \mathrm{ml}) & (1.5 \mathrm{mg} / \mathrm{ml})
\end{array}
$$

\section{XRD}

Crystallite size $(\mathrm{nm})$

$34.8 \pm 5.2 \quad 13.7 \pm 0.9 \quad 13.3 \pm 0.6 \quad 12.1 \pm 1.8$

$\operatorname{TEM}(n=200)$

Mean diameter $<d>(n m)$

Most probable diameter $d_{p}(\mathrm{~nm})$

Dispersion Index $\sigma_{d}$

\section{SQUID}

Saturation mag. $M_{\mathrm{s}}(\mathrm{emu} / \mathrm{g})$ at $300 \mathrm{~K}$

79.2

69.9

59.6

54.8

Saturation mag. $M_{\mathrm{s}}(\mathrm{emu} / \mathrm{g})$ at $5 \mathrm{~K}$

87.7

79.3

68.2

62.9

Coercivity, $H_{\mathrm{c}}(\mathrm{Oe})$ at $300 \mathrm{~K}$

33

9

12

11

Coercivity, $H_{\mathrm{c}}(\mathrm{Oe})$ at $5 \mathrm{~K}$

268

303

281

276

Mean particle diameter $<d>(\mathrm{nm})$

9.1

9.6

9.5

Dispersion Index $\sigma_{d}$

0.29

0.3

0.26

In both thin film and nanoparticle formation, the dominant processes controlling grain size and particle size are crystal growth and nucleation rates [15-17]. The mean grain or particle size $(D)$ is related to both of these parameters by $\langle D\rangle=1.203 \sqrt[3]{G / N}$, where $G$ describes the growth rate and $N$ the nucleation rate. Assuming a constant crystal growth rate, the mean particle size is inversely proportional to the cube root of the nucleation rate, i.e. the higher the nucleation rate the smaller the particles formed. However for constant nucleation rate the particle size varies in proportion to the crystal growth rate. The growth rate of the magnetite is thought to be limited by the thermodynamics of crystal formation, which in these experiments is expected to be relatively constant. In this study, only the biomass levels have been varied, which in turn should lead to an increase in the rate and total amount of $\mathrm{Fe}$ (II) produced within the system at higher biomass levels, hence increasing the probability of nucleation sites being 
formed. An increased nucleation rate caused by the raised biomass concentration would explain the decrease in particle size observed, in accord with the equation given above.

Changes in magnetization across the samples were measured by SQUID magnetometry (figure 3). Ferromagnetic and ferrimagnetic particles become superparamagnetic when their size reaches a critical length, typically below $\sim 30 \mathrm{~nm}$ for magnetite [18], at which point the particle's magnetic moment direction varies randomly due to thermal fluctuations leading to a vanishing magnetic remanence and coercivity. The smaller particles produced in this investigation $\left(\mathrm{OD}_{600}=1,2,4\right)$ all have an average size well below this threshold, and their hysteresis loops (figure 3a) display the characteristic features of superparamagnetism, such as a negligible coercivity $(<10 \mathrm{Oe})$. The plots also show that the saturation magnetisation increases with average particle size from $M_{\mathrm{s}}=62.9 \mathrm{emu} / \mathrm{g}$ for $\mathrm{OD}_{600}=4$ at $5 \mathrm{~K}$, to $87.7 \mathrm{emu} / \mathrm{g}$ for $\mathrm{OD}_{600}=$ 0.4. Bulk magnetite is observed to have $M_{\mathrm{s}} \approx 92 \mathrm{emu} / \mathrm{g}$ [19], which is much larger than that observed for the smallest particles and roughly comparable to the larger particles $\left(\mathrm{OD}_{600}=0.4\right)$. This effect is dependent upon a number of factors, including changes in particle size, the presence of mineral phases such as goethite and siderite, and changes in stoichiometry (relative ratio between $\mathrm{Fe}^{3+}$ and $\mathrm{Fe}^{2+}$ cations) [20, 21].
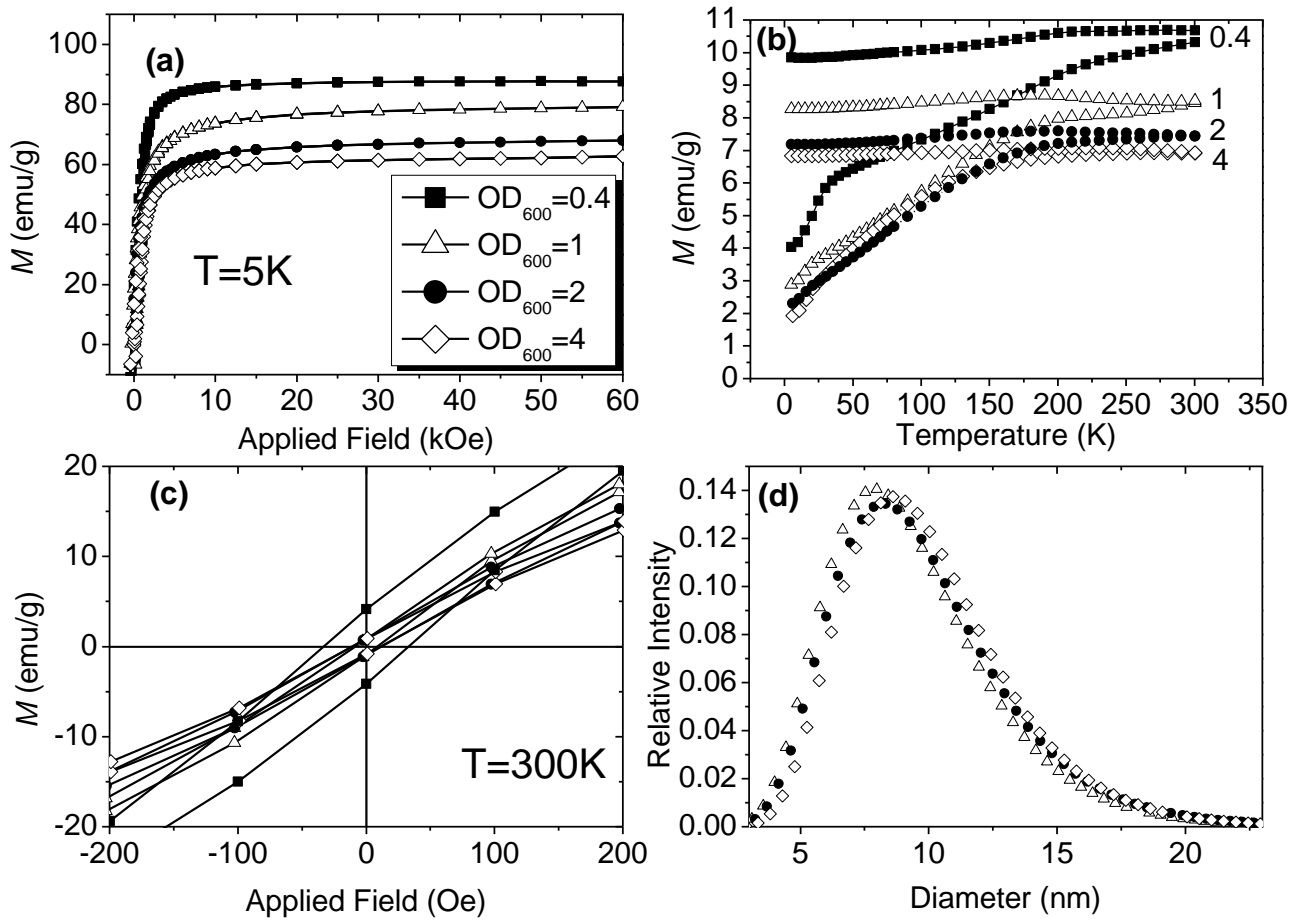

Figure 3. SQUID magnetometry of samples $\mathrm{OD}_{600}=0.4,1,2$ and 4 providing measurements of (a) Saturation magnetisation, (b) Zero-field cooled (ZFC) and field cooled (FC, at $H=100$ Oe) data, (c) Hysteresis loops indicating the coercivity $H_{c}$ of the samples and (d) Particle size distributions obtained through fitting by Langevin functions. 
The temperature above which thermal energy inside a magnetic system is high enough to enable the free alignment of the magnetization in arbitrary directions is called the blocking temperature $\left(T_{\mathrm{B}}\right)$ and can be observed from the zero-field cooled (ZFC) and field cooled (FC) magnetization curves (figure $3 b$ ). The blocking temperature is graphically determined to be the point at which the gradient of the ZFC curve approaches zero. It can be seen that $T_{\mathrm{B}}$ decreases with decreasing particle size, ranging from $\sim 290 \mathrm{~K}\left(\mathrm{OD}_{600}=1\right)$ to $\sim 260 \mathrm{~K}\left(\mathrm{OD}_{600}=2\right.$ and 4$)$. The largest particles $\left(\mathrm{OD}_{600}=0.4\right)$ have a higher blocking temperature and $T_{\mathrm{B}}$ is not well defined but appears to be just above the highest measurement of $300 \mathrm{~K}$. Examination of the TEM image corresponding to this sample (figure 2a) reveals a number of different sized particles with several distinct shapes, hence it could be anticipated that some of these different particles will not exhibit superparamagnetism at room temperature, and are in fact above the threshold of $\sim 30$ $\mathrm{nm}$ for superparamagnetic behaviour. This also explains why a residual coercivity seen in figure $3 \mathrm{c}$ is greater for the $\mathrm{OD}_{600}=0.4$ sample than for the other three samples. This indicates that there is an incomplete superparamagnetic state, i.e. some particles will be superparamagnetic whereas others are not, as reflected in the magnetic measurements which are an average over all these particles. The hysteresis loops are not influenced by the presence of siderite in samples $\mathrm{OD}_{600}=2$ and 4 due to the antiferromagnetism [22] of the additional mineral phase. The Verwey transition observed in bulk magnetite is absent for any of these samples as would be expected in superparamagnetic $\mathrm{Fe}_{3} \mathrm{O}_{4}[1]$.

The form of the magnetisation curve for the superparamagnetic particles is dependent on the magnetic particle volume, and can be neatly described by a Langevin function. Applying a mathematical fit to this curve provides a quantitative analysis of the magnetic particle size distribution [23]. The resulting log-normal distribution can be seen figure $3 \mathrm{~d}$, with the values obtained for mean particle size and most probable particle size listed in table 1. Due to the residual coercivity seen in the largest particles $\left(\mathrm{OD}_{600}=0.4\right)$, an accurate fit was not possible here, as only superparamagnetic curves may be fitted by this method. Mean particle size is seen to be almost equal for samples $\mathrm{OD}_{600}=1,2$ and 4 with values $9.1,9.6$ and $9.5 \mathrm{~nm}$, respectively (we estimate the error due to a small residual coercivity to be $\sim 4 \%$ ) and all have comparable dispersion index values of close to 0.3 , which corresponds to the relative distribution widths. Compared to the results obtained from the TEM images, the mean particle sizes appear to be smaller for the magnetic measurements and also have broader distributions. The reason for this is unclear, however it could be due to a non-magnetic surface layer that has previously been reported in other investigations of magnetite nanoparticles [24, 25].

XMCD measurements were performed on samples prepared in the presence of the redox mediator AQDS, without air exposure in order to preserve the surface oxidation state of the nanoparticles. Biomass concentrations of $\mathrm{OD}_{600}=0.4,1$ and 4 were used, with spectra and relative site occupancies displayed in figure 4 (inset table). The XMCD signal originates only 
from the contribution of magnetic material (the ferrimagnetic magnetite), hence there is no involvement of the antiferromagnetic siderite or goethite.

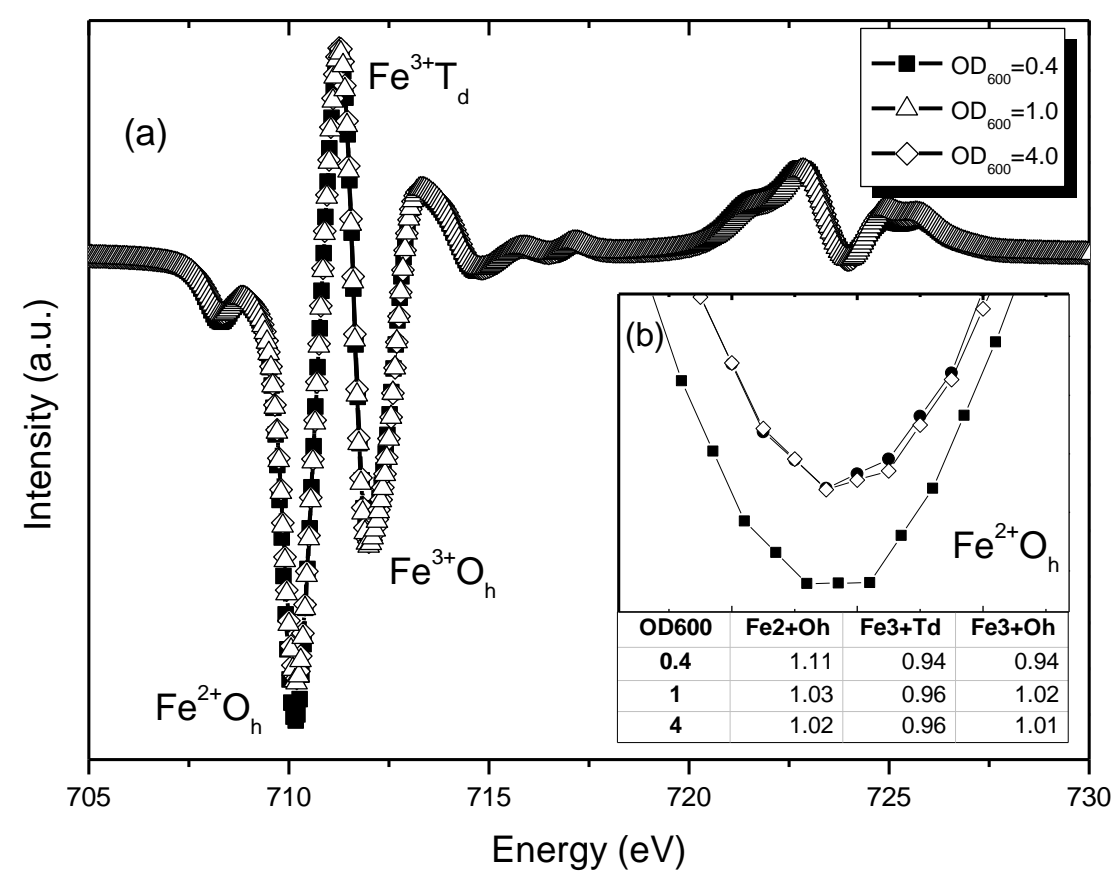

Figure 4. (a) X-ray magnetic circular dichroism of magnetite displaying the characteristic peaks corresponding to $\mathrm{Fe}^{2+}$ and $\mathrm{Fe}^{3+}$ at octahedral sites and $\mathrm{Fe}^{3+}$ at tetrahedral sites in samples of biomagnetite produced with the addition of AQDS and various loadings of G. sulfurreducens. (b) Magnified view of differences in the primary $\mathrm{Fe}^{2+}$ octahedral component.

The Fe $L_{2,3}$ XMCD spectra are characteristic of those expected for magnetite [26, 27]. The results indicate that as particle size decreases, the leading negative peak in the Fe $L_{3}$ edge reduces in magnitude, corresponding to a decline in $\mathrm{Fe}^{2+}$ occupancy on octahedral sites, implying that the samples are becoming less reduced as particle size decreases. Previous work on biogenically produced magnetite has shown the existence of a reduced $\mathrm{Fe}^{2+}$ layer around the particles [28], a result that is considered to have an impact on the surface reactivity of the particles, and could make biogenic magnetite more effective for remediation (e.g. reduction of metals such as $\mathrm{Cr}(\mathrm{VI})$ or reductive dechlorination of solvents) compared to inorganically produced equivalents. Quantitative analysis of the site occupancies by fitting with atomic multiplet calculations $[29,30]$ indicates that the largest particles have a $\mathrm{Fe}^{2+}: \mathrm{Fe}^{3+}$ ratio of 1.18:2, which exceeds the 1:2 ratio expected for stoichiometric magnetite. However the smaller particles have a ratio below that value, with both $\mathrm{OD}_{600}=1$ and 4 showing a $\mathrm{Fe}^{2+}: \mathrm{Fe}^{3+}$ ratio of $1.04: 2$, which is very close to stoichiometric magnetite. 
The results of the XMCD analysis suggests that the smallest measured particles $\left(\mathrm{OD}_{600}\right.$ $=1,4$ ) do not have the $\mathrm{Fe}^{2+}$ rich surface (due to occupancy of $\mathrm{Fe}^{2+} \mathrm{O}_{\mathrm{h}} \sim 1$ ) that is observed for $\mathrm{OD}_{600}=0.4$ and other biogenic magnetite nanoparticles [22]. This apparent difference is due to the surface sensitivity of the technique. In total-electron yield (TEY) mode $\sim 60 \%$ of the signal originates from the top $2 \mathrm{~nm}$ surface layer of the sample, and hence the particle size will affect the relative sampling volume of the particles [31]. As the particle size decreases the effective probing depth is such that almost the entire sample is probed and the measurement is more representative for the bulk. This may explain why the smaller particles appear to be less reduced than the larger particles because the signal from the reduced surface is diluted by that of the bulk material. Shape variations may also have an impact on the XMCD, in relation to the TEY probing depth, as it can be observed from TEM images that the larger particles produced at biomass loading equivalent to $\mathrm{OD}_{600}=0.4$ are made up of square shapes with varying aspect ratios, compared to the more spherical particles produced at higher $\mathrm{OD}_{600}$.

The reactivity of the MNPs produced in this study was measured in relation to their effectiveness at reducing/sequestering a $5 \mathrm{mM}$ aqueous solution of potassium chromate $(\mathrm{Cr}(\mathrm{VI})$ as $\mathrm{K}_{2} \mathrm{CrO}_{4}$ ). The results of an assay specific to chromate (figure 5a) support the supposition that the smaller particles $\left(\mathrm{OD}_{600}=1-4\right)$ would contain greater reducing power due to their larger surface-to-bulk ratio. The larger particles $\left(\mathrm{OD}_{600}=0.2,0.4\right)$ removed $\sim 1 \mathrm{mM} \mathrm{Cr}(\mathrm{VI})$ from solution after $25 \mathrm{~min}$ of reaction time. ICP-AES analysis of the supernatant taken at 42 hours (2520 min) indicated $3.7 \mathrm{mM}( \pm 0.7 \%)$ and $3.4 \mathrm{mM}( \pm 1.4 \%)$ total $\mathrm{Cr}$ remaining in solution prepared with biomass of $\mathrm{OD}_{600}=0.2$ and 0.4 respectively, confirming that only the $\mathrm{Cr}(\mathrm{VI})$ identified by the wet chemical assay remained in solution, and no Cr(III) was present. The three samples with smaller particles initially showed very similar reduction trends to each other, with the removal of more than half $(\sim 2.5 \mathrm{mM})$ of the $\mathrm{Cr}(\mathrm{VI})$ from solution after $25 \mathrm{~min}$. During the 42 hours of the reaction, $\mathrm{Cr}(\mathrm{VI})$ continued to be reduced/sequestered from solution, however at a less intense rate than was first observed. ICP-AES indicated $0.7 \mathrm{mM}( \pm 0.6 \%)$ chromium remaining in solution for the sample prepared with biomass of $\mathrm{OD}_{600}=1$ after 42 hours, and $0.03 \mathrm{mM}( \pm 1 \%)$ and $0 \mathrm{mM}( \pm 6 \%)$ left for those prepared with $\mathrm{OD}_{600}=2$ and 4 respectively after the same time period. It is possible that a small amount of biomass remained on the magnetite samples after washing, however due to the lack of electron donor it is unlikely that bacterial action would have contributed to the reduction of the $\mathrm{Cr}(\mathrm{VI})$. 

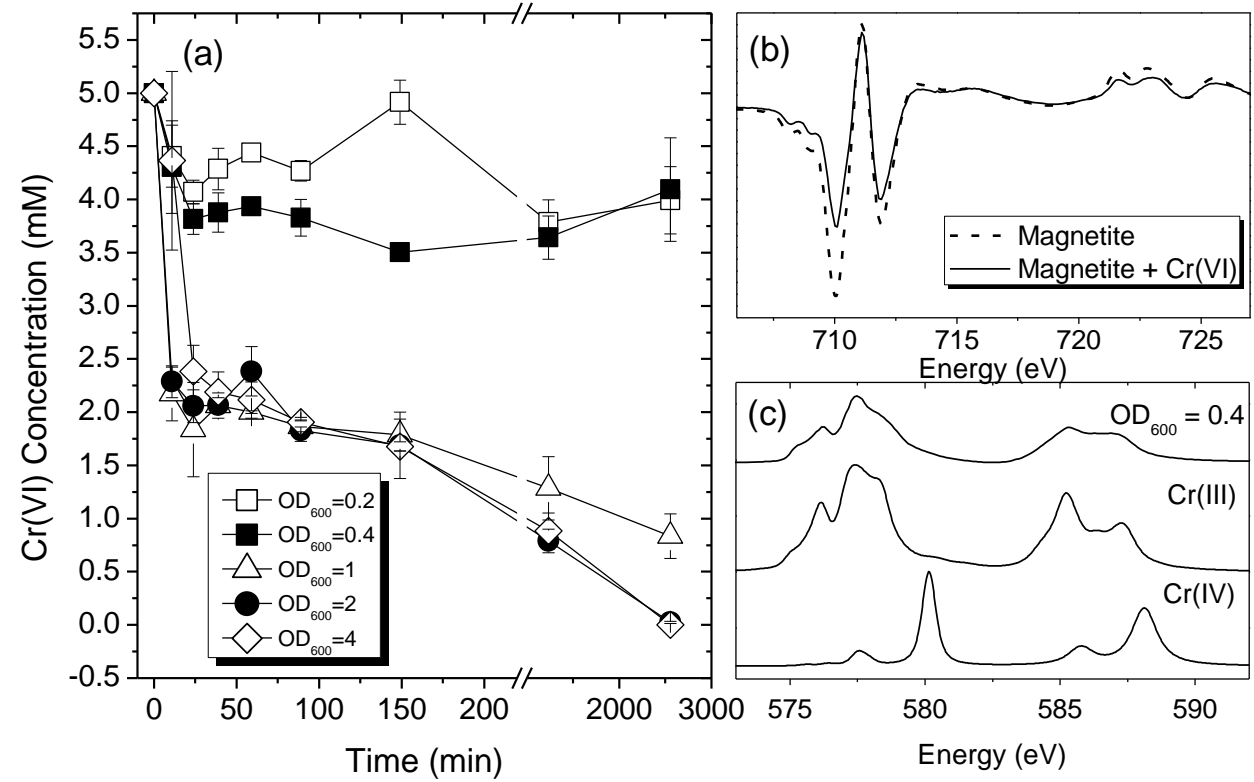

Figure 5. $\mathrm{Cr}(\mathrm{VI})$ reduction and sequestration by magnetite nanoparticles. Magnetic nanoparticles of varying size were added to $\mathbf{5} \mathbf{~ m M}$ potassium chromate solution and left to react for $\mathbf{4 8}$ hours. a) A $\mathrm{Cr}(\mathrm{VI})$ specific spectrophotometric assay was used to measure the amount of $\mathrm{Cr}(\mathrm{VI})$ in solution (error bars determined from standard deviation from the mean absorption reading from samples measured in triplicate). b) XMCD at the Fe $L_{2,3}$ edge was measured to show the crystallographic site location of $\mathrm{Cr}$ incorporation in the $\mathrm{OD}_{600}=0.4$ sample; before addition of chromate (dashed line) and after reaction (solid line). c) XAS indicated the final valence state of the $\mathrm{Cr}$ (III) by comparison to calculated spectra [30].

XAS and XMCD analysis of the reacted MNPs was used to determine the nature of the chromium oxidation state after removal from solution. The results displayed in figures $5 \mathrm{~b}$ and $\mathrm{c}$ correspond to measurements on the sample prepared with biomass of $\mathrm{OD}_{600}=0.4$. Here the first negative peak, corresponding to $\mathrm{Fe}^{2+} \mathrm{O}_{\mathrm{h}}$, is reduced in intensity after reaction with $\mathrm{Cr}(\mathrm{VI})$. Previous studies have shown this result to be due to displacement of $\mathrm{Fe}^{2+}$ in the spinel by chromium in the octahedral site $[11,28]$. Chromium exists in multiple valence states, most notably $\mathrm{Cr}(\mathrm{VI})$ and $\mathrm{Cr}(\mathrm{III})$, and the state incorporated into the magnetite can be determined by examination of the XAS at the $\mathrm{Cr} L_{2,3}$ edge and comparison to standard compounds (figure $5 \mathrm{c}$ ). The spectrum obtained is very similar to that of the calculated $\mathrm{Cr}$ (III) spectrum and shows no similarity to calculated $\mathrm{Cr}(\mathrm{VI})$ spectrum [30]. The calculated spectra show a strong resemblance to the previously measured $\mathrm{Cr}(\mathrm{III})$ and $\mathrm{Cr}(\mathrm{VI})$ containing compounds chromite and crocoite respectively [32]. 


\section{Conclusion}

This study has demonstrated a method for producing size controlled magnetite nanoparticles through the reduction of $\mathrm{Fe}$ (III) minerals by the anaerobic $\mathrm{Fe}$ (III)-reducing bacterium Geobacter sulfurreducens. The average particle size and distribution was varied by adjusting the amount of the whole cell biocatalyst introduced at the start of the experiment, with higher concentrations of bacteria resulting in smaller particles and also leading to narrower size distributions. The mechanism behind this change is thought to be related to the rate of nucleation of the magnetite particles, with higher nucleation rates due an increase in $\mathrm{Fe}^{2+}$ availability with greater biomass concentrations resulting in the production of smaller nanoparticles. The total $\mathrm{Fe}^{2+}$ available also appears to have a bearing on the type of minerals formed in this process, with goethite formed at low biomass (i.e. low $\mathrm{Fe}^{2+}$ ) concentrations, and siderite forming at high biomass (high $\mathrm{Fe}^{2+}$ ) concentrations. A potential application of these different particle sizes has been demonstrated with respect to $\mathrm{Cr}(\mathrm{VI})$ remediation. Smaller particles are shown to be more effective at the reduction/sequestration of $\mathrm{Cr}(\mathrm{VI})$ into the less toxic form of $\mathrm{Cr}$ (III) based on total surface area and for the smallest particles can lead to a complete removal of $\mathrm{Cr}(\mathrm{VI})$ from solution. This result can have important implications for applications where particle size and reactivity must be optimised during production of MNPs, for example in the remediation of land or water contaminated with high valence metals or organics that are susceptible to reductive detoxification. Using a microbiological approach, simple manipulations such as cell densities used during bioproduction can be used to tailor the physical, chemical and magnetic properties of iron nanoparticles. 


\section{Methodology}

A synthetic, amorphous $\mathrm{Fe}(\mathrm{III})$-oxyhydroxide was produced by the precipitation of $0.66 \mathrm{M}$ iron(III) chloride $\left(\mathrm{FeCl}_{3}\right)$ through the addition of sodium hydroxide $(\mathrm{NaOH} ; 10 \mathrm{~N})$ as the hydrolysing agent until reaching a final $\mathrm{pH}$ around 7 [33]. Chloride ions were removed by centrifugation at $17000 \mathrm{~g}$ for $20 \mathrm{~min}$ and washed in deionised water, with the process repeated six times. Total concentration of iron in the final suspension was determined by Ferrozine assay [32].

Geobacter sulfurreducens was grown in anaerobic conditions in the dark at $30^{\circ} \mathrm{C}$ in modified freshwater medium [34] (40 mM sodium fumarate was used as the electron acceptor and $25 \mathrm{mM}$ sodium acetate as the electron donor).

Cultures were prepared in triplicate in deionised water to a total volume of $9.9 \mathrm{ml}$ containing an electron donor (sodium acetate $20 \mathrm{mM}$ ), an electron acceptor (Fe(III)oxhydroxide, $\left.50 \mathrm{mmol} \mathrm{L}^{-1}\right)$, and a sodium bicarbonate buffer $(30 \mathrm{mM})$. All manipulations were carried out under $\mathrm{N}_{2}: \mathrm{CO}_{2}(80: 20)$ gas line to ensure anaerobic conditions were maintained. A number of the cultures also contained the electron shuttle anthraquinone 2,6-disulphonate (10 $\mu \mathrm{M})$ to accelerate $\mathrm{Fe}(\mathrm{III})$-reduction.

Late log-phase cultures of G. sulfurreducens were harvested by centrifugation at 4920 $\mathrm{g}$ and $4^{\circ} \mathrm{C}$, for $20 \mathrm{~min}$ and washed twice in bicarbonate buffer ( $30 \mathrm{mM}$; $\mathrm{pH}$ 7) under a $\mathrm{N}_{2}: \mathrm{CO}_{2}$ (80:20) gas line. Cells were transferred into bicarbonate buffer, forming a total volume of $30 \mathrm{ml}$ bacterial cell suspension. Optical density at $600 \mathrm{~nm}\left(\mathrm{OD}_{600}\right)$ was measured using an M501 single beam scanning UV/visible spectrophotometer.

The cell suspension was diluted with buffer to achieve an $\mathrm{OD}_{600}$ of 0.4 in $10 \mathrm{ml}$ volume $\left(0.2 \mathrm{ml}\right.$ cell suspension, $9.8 \mathrm{ml}$ deionised $\mathrm{H}_{2} \mathrm{O}$ ). Multiples of the $0.2 \mathrm{ml}$ G. sulfurreducens suspension were introduced into each culture depending on the total $\mathrm{OD}_{600}$ desired (e.g. $\mathrm{OD}_{600}=$ 4 required $2.0 \mathrm{ml}, \mathrm{OD}_{600}=2$ required $1.0 \mathrm{ml}$, etc.). Further dilution with buffer was necessary to achieve an $\mathrm{OD}_{600}$ lower than 0.4. Each biomass concentration was repeated in triplicate.

Final concentrations of bacteria in each experiment were determined by protein assay. A volume of $50 \mu \mathrm{l}$ of sample was reacted with $950 \mu \mathrm{BCA}^{\mathrm{B}} \mathrm{CuSO}_{4}$ solution (50:1 bicinchoninic acid to $\left.\mathrm{Cu}(\mathrm{II}) \mathrm{SO}_{4}\right)$. Absorption was measured at a wavelength of $562 \mathrm{~nm}$ against a reference series of Bovine Serum Albumin standards, also reacted with $\mathrm{BCA}^{-\mathrm{CuSO}_{4}}$ after one hour incubation at $30^{\circ} \mathrm{C}$. Optical densities were converted into biomass $(\mathrm{mg} / \mathrm{ml}$ cellular protein) according to: $\mathrm{OD}_{600} 0.015=0.005 \mathrm{mg} / \mathrm{ml}, \mathrm{OD}_{600} 0.03=0.010 \mathrm{mg} / \mathrm{ml}, \mathrm{OD}_{600} 0.05=0.016$ $\mathrm{mg} / \mathrm{ml}, \mathrm{OD}_{600} 0.2=0.06 \mathrm{mg} / \mathrm{ml}, \mathrm{OD}_{600} 0.4=0.142 \mathrm{mg} / \mathrm{ml}, \mathrm{OD}_{600} 0.6=0.220 \mathrm{mg} / \mathrm{ml}, \mathrm{OD}_{600} 0.8$ $=0.297 \mathrm{mg} / \mathrm{ml}, \mathrm{OD}_{600} 1.0=0.375 \mathrm{mg} / \mathrm{ml}, \mathrm{OD}_{600} 2.0=0.763 \mathrm{mg} / \mathrm{ml}, \mathrm{OD}_{600} 4.0=1.54 \mathrm{mg} / \mathrm{ml}$. Cellular protein makes up 50\% of the dry weight mass of the bacteria.

Cultures were incubated in the dark at $30^{\circ} \mathrm{C}$ for 1 week. Magnetite formed was washed twice with deionised water to remove cells and buffer solution. 
$\mathrm{Fe}$ (II) concentrations were measured after the completion of magnetite formation using a Ferrozine assay approach [35]. Cultures were shaken to form a homogeneous solution, $0.1 \mathrm{ml}$ was removed and added to $4.9 \mathrm{ml} 0.5 \mathrm{~N} \mathrm{HCl}$ and incubated for one hour. $0.05 \mathrm{ml}$ of this solution was added to $2.45 \mathrm{ml}$ Ferrozine solution $(2 \mathrm{mM})$ and the $\mathrm{Fe}^{2+}$ concentration measured against a standard curve at $562 \mathrm{~nm}$ in an M501 spectrophotometer.

$\mathrm{Cr}(\mathrm{VI})$ reduction experiments were used to test the reactivity of each biogenic magnetite sample. Bacterial cells and supernatant were removed by magnetic separation and washing, and a solution of $\mathrm{Cr}(\mathrm{VI})$ (potassium chromate, $\mathrm{K}_{2} \mathrm{CrO}_{4}, 5 \mathrm{mM}$ ) added to make up a total volume of $10 \mathrm{ml}$. All bottles had an anaerobic headspace and were stored at $20^{\circ} \mathrm{C}$ in the dark on a continuous roller-mixer at $33 \mathrm{rpm}$. The $\mathrm{Cr}(\mathrm{VI})$ remaining in solution was measured at frequent intervals using a diphenyl carbazide (DPC) spectrophotometric assay [36]. Each experiment was repeated in triplicate, with $\mathrm{Cr}(\mathrm{VI})$ concentration remaining in solution determined as the mean of the three, with error bars determined as the standard deviation from the mean.

Powder X-ray diffraction (PXRD) measurements were carried out using a Bruker D8Advance with $\mathrm{Cu} K_{\alpha 1}$ source. Data was acquired over a $2 \theta$ range of $5^{\circ}-70^{\circ}$ with a step size of $0.02^{\circ}$. Where magnetite formation was observed, the average particle size was determined by

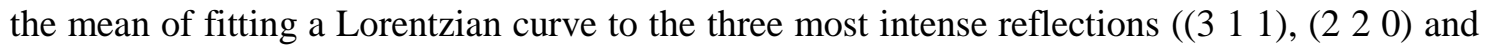
(4 4 0)) and measuring the full width half maximum and Bragg angle; these values were used to determine particle size via input into the Scherrer equation [37,38]. Error bars were determined as the standard deviation from the mean of the three fits. Fitting of the Lorentzian curve was performed using OriginPro 8.1 SR3 (OriginLab Corporation) software.

$\mathrm{X}$-ray magnetic circular dichroism (XMCD), derived from the X-ray absorption spectroscopy (XAS) spectra at the Fe $L_{2,3}$-edge, were measured at the Advanced Light Source (ALS), Lawrence Berkeley National Laboratory, California. The XMCD spectrum is the difference between the absorption of circularly polarized X-rays measured for two opposite magnetisation directions $( \pm 0.6 \mathrm{~T})$ parallel and antiparallel to the beam direction. The XMCD spectrum changes, depending upon magnetisation, site location and valence state (number of $d$ electrons). Atomic multiplet calculations can be applied to XMCD and XAS spectra to determine site distributions of Fe cations within the structure of the crystalline material [29, 30]. Samples were dried and ground in an anaerobic cabinet and mounted onto carbon tape attached to the sample probe with transportation to the beamline taking place in a sealed anaerobic container to minimise potential exposure to air. Measurements were made in totalelectron yield mode (TEY) with an effective probing depth of $\sim 3-4 \mathrm{~nm}$.

Transmission electron microscopy (TEM) was carried out at the Leeds Electron Microscopy And Spectroscopy (LEMAS) Centre, University of Leeds, UK using a Philips CM 200 electron microscope equipped with a field emission gun (FEG), EDX detector (Oxford 
Instruments, ISIS software) and Gatan imaging filter (GIF200). All images are obtained using an accelerating voltage of $200 \mathrm{kV}$. Direct measurement of the images were carried out to determine average particle size using a population size of $n=200$ particles per sample.

Magnetic measurements were performed on polycrystalline samples restrained in eicosane, using a Quantum Design MPMS-XL SQUID magnetometer equipped with a $7 \mathrm{~T}$ magnet. Zero-field cooled (ZFC) and field-cooled (FC) magnetisation curves were recorded over 5-300 K temperature range with an applied magnetic field of 100 Oe. The diamagnetism of the sample holder and of eicosane was measured and extracted from the raw magnetic data. 


\section{Acknowledgements}

This work was carried out with the financial support of a NERC PhD studentship awarded to James Byrne. The Advanced Light Source is supported by the Director, Office of Science, Office of Basic Energy Sciences, of the U.S. Department of Energy under Contract No.DEAC02-05CH11231. We acknowledge NERC Envirosync II for providing support for this work. Additional thanks to Dr. Michael Ward for assistance and the provision of access to Transmission Electron Microscope by Leeds Nanoscience and Nanotechnology Facility (LENNF). 


\section{References}

[1] Goya G F, Berquo T S, Fonseca F C and Morales M P Static and dynamic magnetic properties of spherical magnetite nanoparticles. Journal of Applied Physics 2003, 94, 3520-3528.

[2] Hencl V, Mucha P, Orlikova A and Leskova D Utilization of Ferrites for WaterTreatment. Water Research 1995, 29, 383-385.

[3] Johannsen M, Gneveckow U, Thiesen B, Taymoorian K, Cho C H, Waldöfner N, Scholz $\mathrm{R}$, Jordan A, Loening, S A and Wust P Thermotherapy of prostate cancer using magnetic nanoparticles: feasibility, imaging, and three-dimensional temperature distribution. European Urology 2007, 52, 1653-1662.

[4] Kim D-H, Nikles D E, Johnson D T and Brazel C S Heat generation of aqueously dispersed $\mathrm{CoFe} 2 \mathrm{O} 4$ nanoparticles as heating agents for magnetically activated drug delivery and hyperthermia. Journal of Magnetism and Magnetic Materials 2008, 320, 2390-2396.

[5] Majewski P and Thierry B Functionalized magnetite nanoparticles - Synthesis, properties, and bio-applications. Critical Reviews in Solid State and Materials Sciences 2007, 32, 203-215.

[6] Ritter J A, Ebner A D, Daniel K D and Stewart K L Application of high gradient magnetic separation principles to magnetic drug targeting. Journal of Magnetism and Magnetic Materials 2004, 280, 184-201.

[7] Mizutani N, Iwasaki T, Watano S, Yanagida T and Kawai T Size control of magnetite nanoparticles in hydrothermal synthesis by coexistence of lactate and sulfate ions. Current Applied Physics 2009, 10, 801-806.

[8] Hansel C M, Benner S G, Neiss J, Dohnalkova A, Kukkadapu R K and Fendorf S Secondary mineralization pathways induced by dissimilatory iron reduction of ferrihydrite under advective flow. Geochimica Et Cosmochimica Acta 2003, 67, 29772992.

[9] Hansel C M, Benner S G and Fendorf S Competing Fe(II)-induced mineralization pathways of ferrihydrite. Environmental Science \& Technology 2005, 39, 7147-7153.

[10] Peterson M L, White A F, Brown G E and Parks G A Surface Passivation of Magnetite by Reaction with Aqueous Cr(VI): XAFS and TEM Results. Environmental Science \& Technology 1997, 31, 1573-1576.

[11] Telling N D, Coker V S, Cutting R, S, van der Laan G, Pearce C I, Pattrick R A D, Arenholz E and Lloyd J R Remediation of $\mathrm{Cr}(\mathrm{VI})$ by biogenic magnetic nanoparticles: An X-ray magnetic circular dichroism study. Applied Physics Letters 2009, 95, 163701$1 / 3$ 
[12] Coker V, Pattrick R A D, van der Laan G and Lloyd J Formation of Magnetic Minerals by Non-Magnetotactic Prokaryotes. Magnetoreception and Magnetosomes in Bacteria, Series Microbiology Monographs, Ed. Schüler D (Springer, Heidelberg 2006), ISSN 1862-5576 (Print); 1862-5584 (Online) 2007; pp 275-300.

[13] Lovley D R, Fraga J L, Blunt-Harris E L, Hayes L A, Phillips E J P and Coates J D Humic substances as a mediator for microbially catalyzed metal reduction. Acta Hydrochimica Et Hydrobiologica 1998, 26, 152-157.

[14] Cornell R M, Schwertmann U, The Iron Oxides: Structure, Properties, Reactions, Occurrences and Uses; Wiley-VCH, Weinheim, Germany, 2003 pp 388-401.

[15] Momose S, Kodama H, Uzumaki T and Tanaka A Fine tuning of the sizes of FePt nanoparticles. Japanese Journal of Applied Physics Part 1-Regular Papers Brief Communications \& Review Papers 2005, 44, 1147-1149.

[16] Nandwana V, Elkins K E, Poudyal N, Chaubey G S, Yano K and Liu J P Size and Shape Control of Monodisperse FePt Nanoparticles. The Journal of Physical Chemistry C 2007, 111, 4185-4189.

[17] Vopsaroiu M, Fernandez G V, Thwaites M J, Anguita J, Grundy P J and O'Grady K Deposition of polycrystalline thin films with controlled grain size. Journal of Physics $D$ Applied Physics 2005, 38, 490-496.

[18] Dunlop D J and Ozdemir O Rock Magnetism: Fundamentals and Frontiers., In Cambridge studies in magnetism; Cambridge University Press, New York, 1997.

[19] Jacobs I S Evidence for triangular moment arrangements in MO $\cdot \mathrm{Mn} 2 \mathrm{O} 3$. Journal of Physics and Chemistry of Solids 1959, 11, 1-11.

[20] Berkowitz A E, Schuele W J and Flanders P J Influence of crystallite size on magnetic properties of acicular $\gamma-\mathrm{Fe}_{2} \mathrm{O}_{3}$ particles. Journal of Applied Physics 1968, 39, 1261-1/3.

[21] Lu H M, Zheng W T and Jiang Q Saturation magnetization of ferromagnetic and ferrimagnetic nanocrystals at room temperature. Journal of Physics D-Applied Physics 2007, 40, 320-325.

[22] Coker V S, Telling N D, van der Laan G, Pattrick R A D, Pearce C I, Arenholz E, Tuna, F, Winpenny R E P, and Lloyd J R Harnessing the Extracellular Bacterial Production of Nanoscale Cobalt Ferrite with Exploitable Magnetic Properties. ACS Nano 2009, 3, 1922-1928.

[23] Jacobs I S, Metamagnetism of Siderite $\left(\mathrm{FeCO}_{3}\right)$. J. Appl. Phys. 1963, 34, 1106.

[24] Pal S, Dutta P, Shah N, Huffman G P and Seehra M S Surface spin disorder in Fe3O4 nanoparticles probed by electron magnetic resonance spectroscopy and magnetometry. IEEE Transactions on Magnetics 2007, 43, 3091-3093. 
[25] Dutta P, Pal S, Seehra M S, Shah N and Huffman G P Size dependence of magnetic parameters and surface disorder in magnetite nanoparticles. Journal of Applied Physics 2009, 105, 07B501-1/-3.

[26] Pattrick R A D, van der Laan G, Henderson C M B, Kuiper P, Dudzik E and Vaughan D J Cation site occupancy in spinel ferrites studied by X-ray magnetic circular dichroism: developing a method for mineralogists. European Journal of Mineralogy 2002, 14, 1095-1102.

[27] Pearce C I, Henderson C M B, Pattrick R A D, van der Laan G and Vaughan D J Direct determination of cation site occupancies in natural ferrite spinels by L2,L3 X-ray absorption spectroscopy and X-ray magnetic circular dichroism. American Mineralogist 2006, 91, 880-893.

[28] Cutting R S, Coker V S, Telling N D, Kimber R L, Pearce C I, Ellis B L, Lawson R S, Van der Laan G, Pattrick R A D, Vaughan D J, Arenholz E and Lloyd J R Optimizing $\mathrm{Cr}(\mathrm{VI})$ and $\mathrm{Tc}(\mathrm{VII})$ Remediation through Nanoscale Biomineral Engineering.

Environmental Science \& Technology 2010, 44, 2577-2584.

[29] van der Laan G and Kirkman I W The 2p Absorption Spectra of 3d Transition-Metal Compounds in Tetrahedral and Octahedral Symmetry. Journal of Physics-Condensed Matter 1992, 4, 4189-4204.

[30] van der Laan G, and Thole B T Strong Magnetic-X-Ray Dichroism in 2p AbsorptionSpectra of 3d Transition-Metal Ions. Physical Review B 1991, 43, 13401-13411.

[31] Stohr J and Siegmann H C X-rays and Magnetism: Spectroscopy and Microscopy. Magnetism From Fundamentals to Nanoscale Dynamics, Springer Berlin Heidelberg: 2006; pp 431-476.

[32] Kendelewicz T, Liu P, Doyle C S, Brown Jr G E, Nelson E J and Chambers S A X-ray absorption and photoemission study of the adsorption of aqueous $\mathrm{Cr}(\mathrm{VI})$ on single crystal hematite and magnetite surfaces. Surface Science 1999, 424, 219-231.

[33] Lovley D R and Phillips E J P Availability of ferric iron for microbial reduction in bottom sediments of the fresh-water tidal potomac river. Applied and Environmental Microbiology 1986, 52, 751-757.

[34] Lloyd J R, Leang C, Myerson A L H, Coppi M V, Cuifo S, Methe B, Sandler S J and Lovley D R Biochemical and genetic characterization of PpcA, a periplasmic c-type cytochrome in Geobacter sulfurreducens. Biochemical Journal 2003, 369, 153-161.

[35] Stookey L L Ferrozine - A new spectrophotometric reagent for iron. Analytical Chemistry 1970, 42, 779-\&.

[36] Skougstad M W, Fishman M J, Friedman L C, Erdman D E and Duncan S S Method for determination of Inorganic Substances in Water and Fluvial. US Geological Survey 1979, 5. 
[37] Scherrer P Estimation of Size and Internal Structure of Colloidal Particles by Means of Rontgen Rays. Nachr. Ges. Wiss. Goettingen 1918, 96-100.

[38] Patterson A L The Scherrer formula for X-ray particle size determination. Physical Review 1939, 56, 978. 
This document was prepared as an account of work sponsored by the United States Government. While this document is believed to contain correct information, neither the United States Government nor any agency thereof, nor the Regents of the University of California, nor any of their employees, makes any warranty, express or implied, or assumes any legal responsibility for the accuracy, completeness, or usefulness of any information, apparatus, product, or process disclosed, or represents that its use would not infringe privately owned rights. Reference herein to any specific commercial product, process, or service by its trade name, trademark, manufacturer, or otherwise, does not necessarily constitute or imply its endorsement, recommendation, or favoring by the United States Government or any agency thereof, or the Regents of the University of California. The views and opinions of authors expressed herein do not necessarily state or reflect those of the United States Government or any agency thereof or the Regents of the University of California. 